\title{
Variability in Spatial Distribution of Precipitation Overall Rugged Topography of Lebanon, Using TRMM Images
}

\author{
Ihab Jomaa ${ }^{*}\left(\mathbb{D}\right.$, , Marie Therese Abi Saab ${ }^{2}$, Sleiman Skaf1, Nisrine El Haj ${ }^{1}$, Randa Massaad ${ }^{1}$ \\ ${ }^{1}$ Lebanese Agricultural Research Institute, Tal Amara, Lebanon \\ ${ }^{2}$ Lebanese Agricultural Research Institute, Fanar, Lebanon \\ Email: *ijomaa@lari.gov.lb
}

How to cite this paper: Jomaa, I., Saab, M.T.A., Skaf, S., El Haj, N. and Massaad, R. (2019) Variability in Spatial Distribution of Precipitation Overall Rugged Topography of Lebanon, Using TRMM Images. Atmospheric and Climate Sciences, 9, 369-380. https://doi.org/10.4236/acs.2019.93026

Received: April 5, 2019

Accepted: July 9, 2019

Published: July 12, 2019

Copyright $\odot 2019$ by author(s) and Scientific Research Publishing Inc. This work is licensed under the Creative Commons Attribution International License (CC BY 4.0).

http://creativecommons.org/licenses/by/4.0/

\begin{abstract}
Rain gages data represents limited spatial coverage, especially in rugged terrains like Lebanon. Other precipitation data sources are the developing satellite and radar technologies. In this study, Tropical Rain Measurement Mission (TRMM) monthly rainfall data of 18 years (1998-2014 and 2017) was used to understand monthly and yearly precipitation spatial distribution overall Lebanon. Topographic effect of rainfall spatial distribution was investigated in comparison to Plassard's map of 1971. The annual precipitation over the country ranged between $850 \mathrm{~mm}$ and $200 \mathrm{~mm}$ that differs than the existing historical map. The maximum rainfall rate decreased by about 700 mm between the derived TRMM rainfall map and Plassard's one. Spatial distribution of maximum precipitation rates does not coincide between maps. TRMM map of elevated terrains did not show similar trends of rainfall distribution as Plassard's. Pixels (Lebanon was divided into 27 pixels) of lower rainfall rates was found toward the eastern side of Lebanon, in contrast to Plassard's results. Anti-Lebanon did not show an increase in precipitation in accordance to altitude. Spatial variability of precipitation was about $50 \mathrm{~mm}$ between pixels which reveals the importance of considering topography while implemented rain gages as observation points. TRMM and satellite rainfall data aid in investigating complete spatial distribution of rainfall over continuous periods. Accumulating knowledge of spatial rainfall distribution on timely basis will lead to better future modelling on floods and drought conditions in Lebanon.
\end{abstract}

\section{Keywords}

TRMM Data, Rainfall, Plassard's Map, Lebanon, Topography 


\section{Introduction}

Observation points have been the main source of rainfall distribution for more than a century. Rain gages are placed at spatial network of coverage, seeking representative localities for larger area depiction [1]. However, users of rainfall data, especially, watershed hydrological modeler and agriculture management, are faced by low spatial accuracy while interpolating rainfall gages point readings. On catchment level, runoff estimation is never precise without accurate spatial reproduction of rainfall distribution to cover the whole watershed area [2] [3] [4] [5]. Since the 1980s, precipitation is being recorded on continuous spatial scale, using satellite rainfall products. Research is conducted, henceforth, to improve precipitation data collection of satellite images [6] [7].

Rainfall satellite products are becoming numerous in global and regional coverage. Among these satellites, products are CHIRPS (Climate Hazards Group InfraRed, Precipitation with Station data), RFE (NOAA's Africa Rainfall Estimates), CPC (NOAA's Climate Prediction Center), TRMM (Tropical Rainfall Measuring Mission), and GPM (Global Precipitation Measurement). Remote sensing is the other approach of rainfall measurement that captures variability on temporal and spatial scale, in comparison to gages. Nonetheless, ground-based radar technologies are providing temporal resolution of less than five minutes with spatial coverage of about a square kilometer [8]. Understanding the spatiotemporal characteristics of precipitation remains challenging where science is investigating new ground-based remote sensing technologies.

Lebanon, of rugged topography, has mainly orographic precipitation type. The orographic effect is caused by rising air masses on a forefront windward slope to the west. Mediterranean Sea humid air travels uplands on Mount-Lebanon chain, working along the coast as facing barrier. Rising air condenses, causing to have littoral side thunderstorms. Rain shadow occurs after the air descends on the leeward side of the mountain to the east. Descending air is drier because of the heavy rainfall events poured on the mountain windward side. Lower rainfall rates are registered to the inlands at the rain shadow side of Mount-Lebanon. Topographic complexity of mountain regions, over the country, causes high spatial variability of precipitation.

Most rainfall data overall Lebanon lacks consistency in time and space. Historical data of recorded gages, prior 1974, are considered the most reliable manually registered information on rainfall distribution for the country. Currently, the large network of rain gages of automated types (Automated Weather Station-AWS) are distributed in agriculture areas belongs to the Lebanese Agriculture Research Institute (LARI). Nonetheless, manual rain gages (twelve in total) are distributed in LARI promises at different regions. Other institutions (Lebanese Meteo Service), universities, ministries (environment and agriculture), NGO owns AWS. As an estimate, the total AWS among all bodies reach to about 150 AWS. Representative spatial distribution of rainfall gages is not well understood, in Lebanon, even having a precipitation map produced in the 1970s, 
using observation point data source [9].

This study focused on temporal and spatial variability of rainfall, overall Lebanon, for the sake of knowing homogeneous areas for representative distribution of point observation gages. Specifically, it studied the temporal variability of rainfall on monthly and yearly resolution. The study analyzed the possibility of using TRMM grid data for spotting homogeneous spatial distribution areas of rainfall. Nevertheless, comparison was performed between previous spatial distribution of rain in Plassard map and TRMM data.

\section{Materials and Methods}

\subsection{Lebanon Rainfall Characteristics}

Complex topography over Lebanon is caused by the presence of mountains that touches the sea and spreads inlands. Valleys, mountain depressions, elevated peaks (highest $3088 \mathrm{~m}$ a.s.l.), inland plains, two mountain chains characterizes the geomorphology of the country. Humid sea wind is blocked by Mount-Lebanon chain, having southwest to northeast direction. Anti-Lebanon mountain chain runs parallel to Mount-Lebanon chain with separating plateau (Bekaa Plain) average width of $40 \mathrm{~km}$ (Figure 1).

Topography plays an important role in rainfall variability over Lebanon. Rainfall patterns range from over $1000 \mathrm{~mm}$ at the northern coastal area, reaching less than $200 \mathrm{~mm}$ at the northeastern area. [9] produced the rainfall distribution map of Lebanon showing various patterns in harmony to altitude levels (Figure 2). Rainfall ranges are fourteen of $100 \mathrm{~mm}$ resolution. It seems that the effect of topography is easily interpreted through elevation variability. Orographic pattern of rainfall is well pronounced in Plassard rainfall map.

Peak precipitation occur at the coastal areas with rainy shadow exists at the inland. The orographic rainfall occurs overall Lebanon except the southern region. Rainfall season is limited to the period between September and May. December, January are the rainiest months vs mostly null precipitation in summer period. Intense heating might cause precipitation to occur in summer months for one to two events in rare occasions.

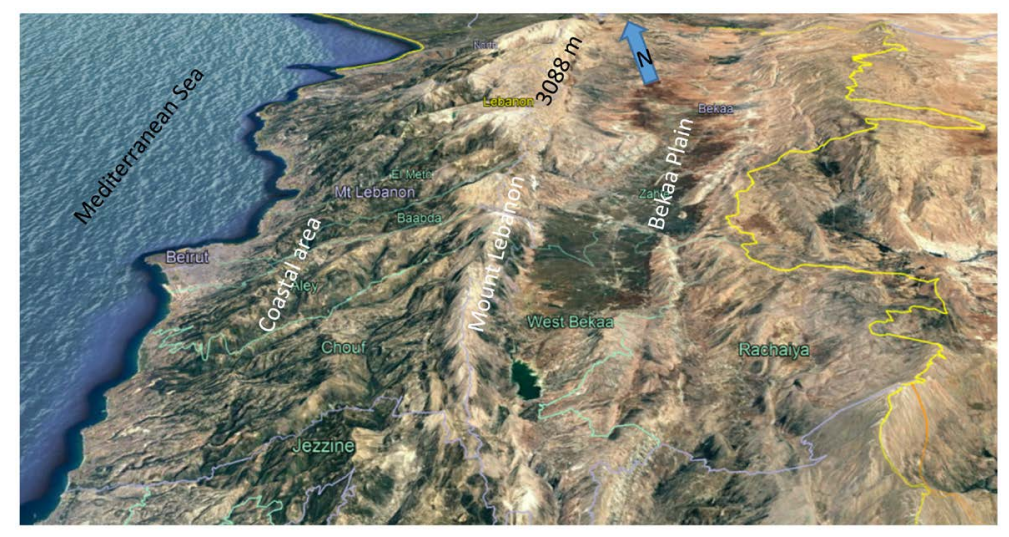

Figure 1. Geomorphology of Lebanon (modified from Google Earth). 


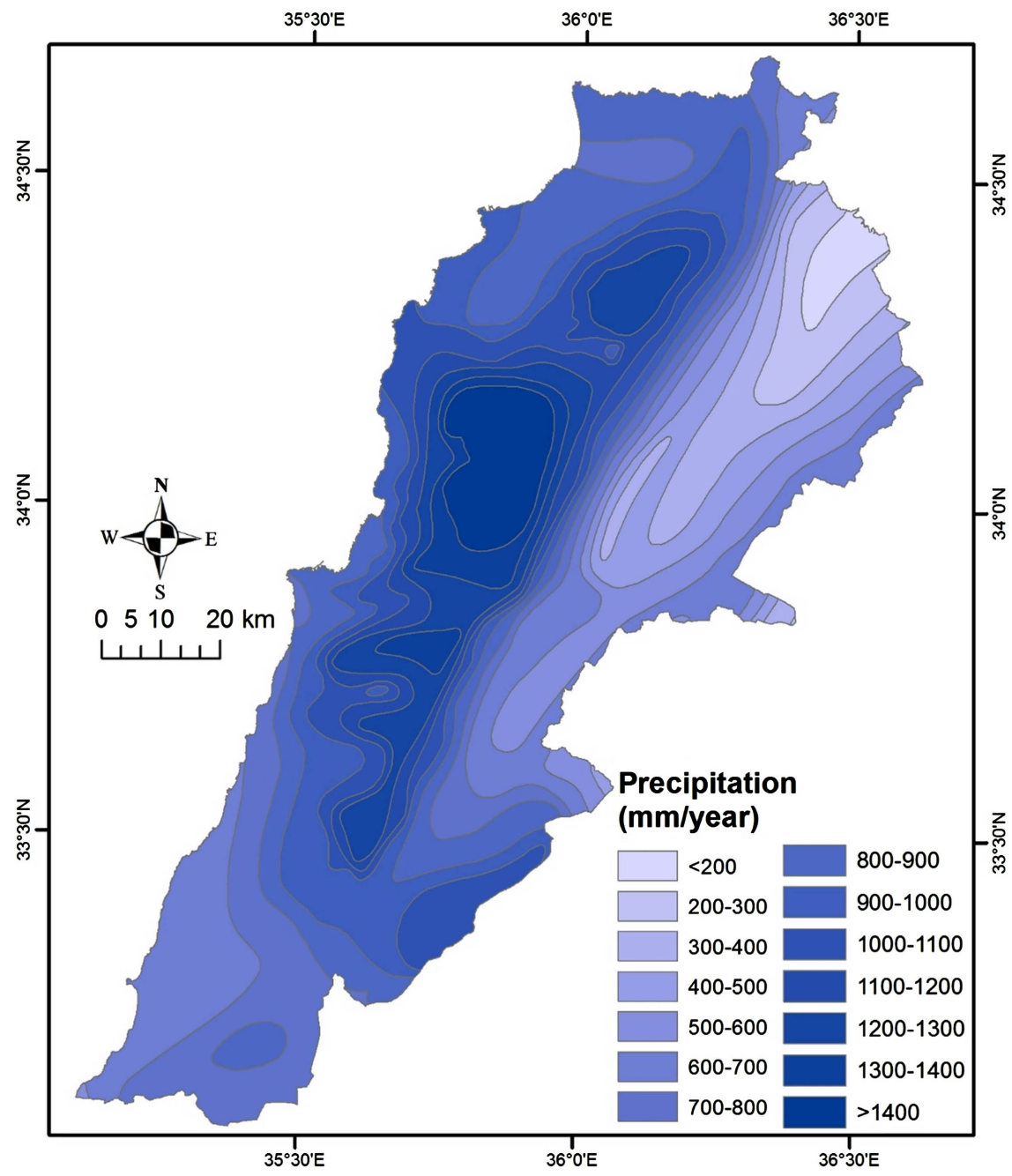

Figure 2. Rainfall map of Lebanon (modified from Plassard, 1971).

\subsection{Rainfall Remote Sensing Data}

The Tropical Rainfall Measurement Mission (TRMM) is a joint space mission between NASA and Japan's National Space Development Agency. TRMM was designed to monitor precipitation over oceans and lands in the regions of tropical and subtropical.

TRMM PR monthly product (3B42, merged $3 \mathrm{~B}-42$ and rain gauge estimates) at a spacing of $0.25 \times 0.25$ degree (about long $23 \mathrm{~km}$ and lat $27 \mathrm{~km}$ ) (TRMM and other sources estimates) was used in this study. TRMM gridded data for the period of 1998-2017 (excluding 2015 and 2016) was used of monthly mean of $\mathrm{mm} /$ hour. The $3 \mathrm{~B} 42$ data is adjusted to rain gages data for further verification and adjustment for rainfall biases. The combining precipitation dataset follows the concept of Huffman et al. (1995) [10].

\subsection{Data Processing}

Monthly precipitation gridded data was clipped from globe-size to cover entire 
Lebanon, using GIS facilities (ArcGIS version 10.3). Precipitation layers were converted to the unit of $\mathrm{mm} / \mathrm{month}$. Statistical analysis was performed to study the spatial variability among consecutive years. The rainy season was searched for its mean and standard deviation in each gridded pixel on monthly basis. The gridded pixels were not smoothed in GIS, but they were kept to differential between mean and standard deviation values.

Lebanon was divided into 27 grid cells of $0.25^{\circ} \times 0.25^{\circ}$ and numbered southward. Each cell was registered for its average rain of eighteen years and their standard deviation.

\section{Results and Discussion}

\subsection{Rainfall Patterns within and among Months}

End summer season, precipitation begins to fall in September. TRMM data, in September, demonstrates a spatial distribution that depends mainly on the orographic effect over Mount-Lebanon peaks. The highest rates of rain (about 15 $\mathrm{mm} / \mathrm{month}$ ) fall over the northern coastal zone of Lebanon. Remaining humidity of air drips rain over the leeward side of the mountain. Thus in September, the monthly average precipitation rate, at the leeward side, comes to about 5 $\mathrm{mm} / \mathrm{month}$ at the top northern pixel numbered C7. Moving about $27 \mathrm{~km}$ southward, to pixel $\mathrm{C} 12$, precipitation rate decreases to about $2 \mathrm{~mm} / \mathrm{month}$. It is obvious that the pixel C7 is mostly of mountainous topographic feature (part from Mount Lebanon chain). On the other hand, C12 pixel is divided between the Bekaa Plain and Anti Lebanon mountain chains. Other parts of Lebanon receive trace or little precipitation during the month of September (Figure 3).

Consequently, a rain gage placed in $\mathrm{C} 7$ will not indicate the amount of rainfall in C12. Pixel number C7 has also a portion of the Bekaa plain, where if a rain gage was placed over this area, it will cause a misleading of rainfall spatial distribution. This applies to other pixels over the Bekaa Plain, e.g., C17 is a location where rainfall rates in September comes to almost null.

Similarly, precipitation over the south coastal zone is also minim in pixel numbers C21 to C27. The hilly areas of south Lebanon do not cause orographic rain to form. Rainfall remains almost constant, starting from the coast C26 toward C27.

In October, precipitation starts to distribute widely over the country. Rainfall remains concentrated to the northern coast but with spatial extension southward to about $\mathrm{C} 15$, although precipitation reached the inland area, but with low rates.

In November, precipitation becomes spatially distributed overall Lebanon. Rainfall remains concentrated over northern coast but extends southward. In inland areas, toward C18 and C22, rainfall is the lowest for the whole fall period.

Precipitation in December progressed further southward in the coastal area. Inland precipitation rates increased by about six times from 10 to $60 \mathrm{~mm}$. Rainfall toward C13, C18 and C22 remains the lowest compared to other parts of the country. 


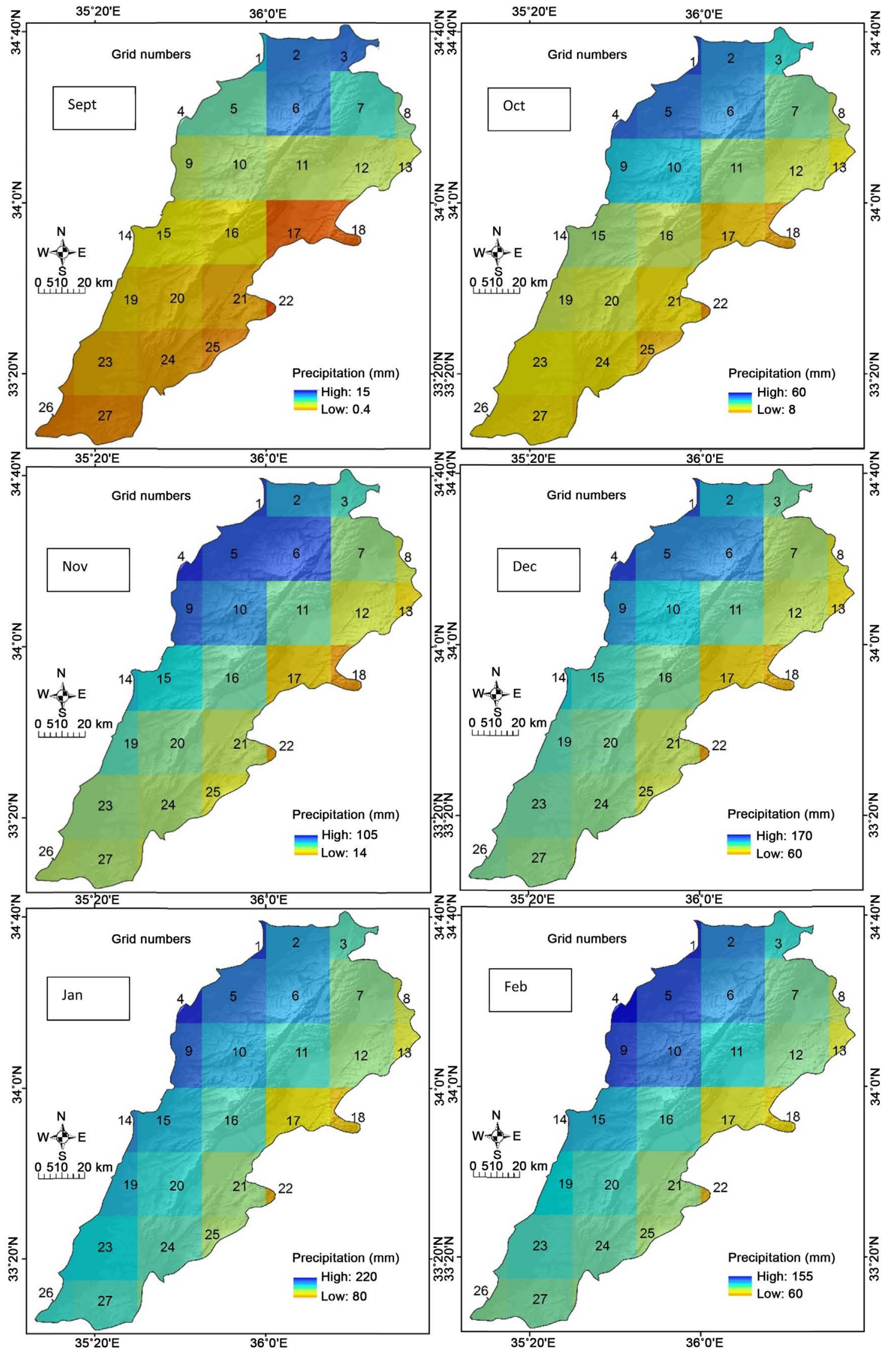



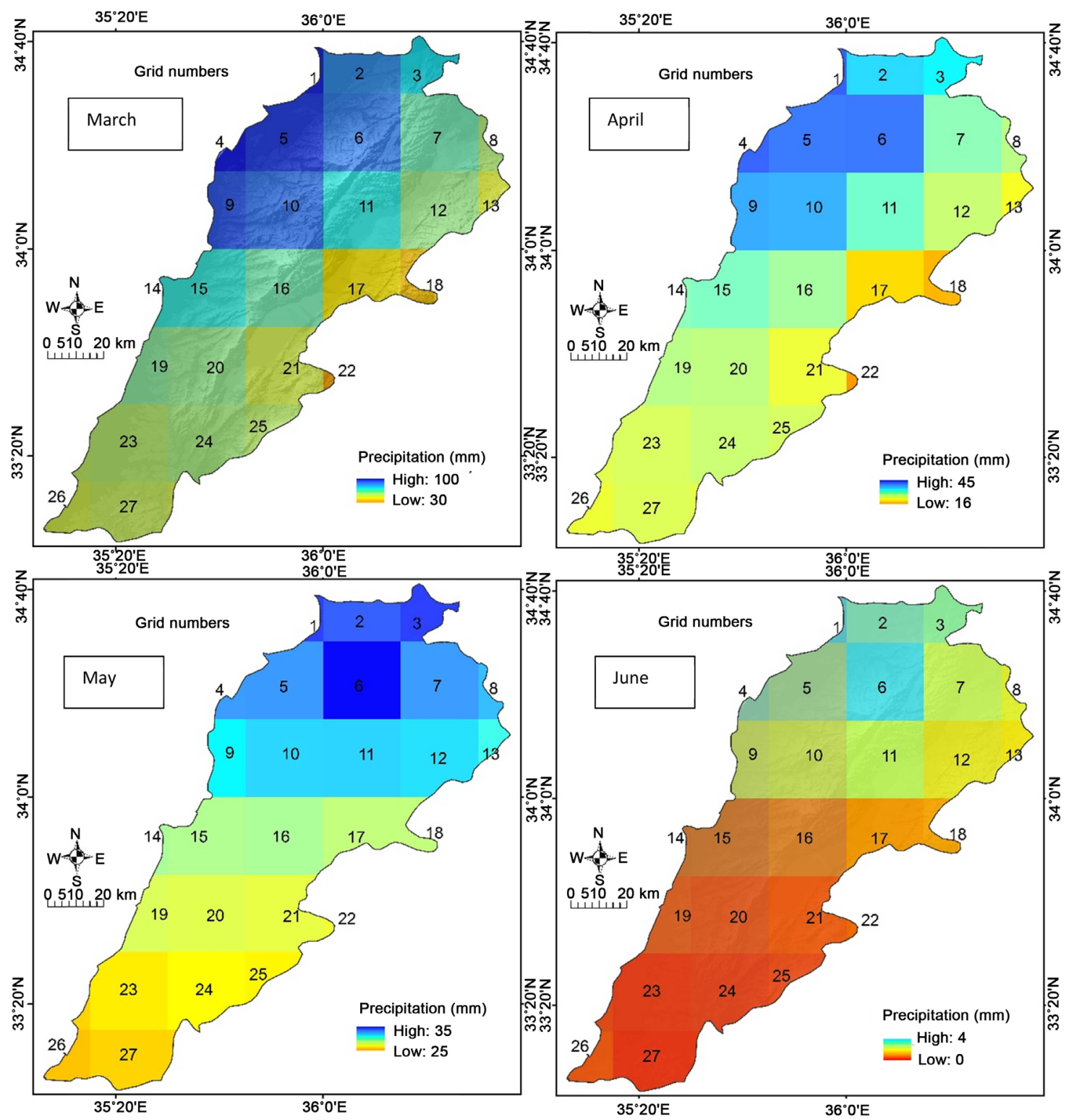

Figure 3. September to February spatial distribution of rainfall overall Lebanon, based on TRMM data (Note: each map has its own color ramp scale). March to June spatial distribution of rainfall overall Lebanon, based on TRMM data (Note: each map has its own color ramp scale).

January rainfall is more distributed overall the country. Rainy season peak-precipitation rate is in January. Along the seashore, precipitation is the highest and Mount-Lebanon receives most of the precipitation toward westward slope. The difference between the seashore pixel number $\mathrm{C} 4(220 \mathrm{~mm})$ and neighboring one C5 $(170 \mathrm{~mm})$ is $50 \mathrm{~mm}$. This difference of $50 \mathrm{~mm}$ is repeated over the pixels C16 (145 $\mathrm{mm})$ and C17 $(90 \mathrm{~mm})$.

Rainfall distribution in February is very similar to January. The same January trend of precipitation was found along the seashore. Nonetheless, precipitation decreased with topographic elevation over the windward side of Mount-Lebanon. Precipitation are getting almost equal between pixels located at C4 and C5 with a 
difference of about $10 \mathrm{~mm}$.

March is the month when precipitation starts to concentrate more against the northern seashore. It appeared that precipitation is moving back toward the northern coastal part of the country. The difference of precipitation between $\mathrm{C} 4$ and $\mathrm{C} 5$ becomes about $5 \mathrm{~mm}$ only.

Precipitation of April is more focused over the northern coast. The seashore rain is very unequal, ranging between 45 and $20 \mathrm{~mm}$. Precipitation difference is less than $4 \mathrm{~mm}$ between $\mathrm{C} 4$ and C5.

Precipitation in May is mainly in northern Lebanon. Similar to early fall, last rainy season has the highest rainfall rates over the pixel number C6. The Orographic effect is more shown at the northern part of Lebanon. The highest peak of Mount-Lebanon receives the highest precipitation rate but it is noticeable that precipitation becomes almost of equal on both side of the mountain slope. Inland and coastal precipitation becomes equal. This fact means that the intensity of precipitation is alike, once considering that TRMM data is recorded over 3 hour time period.

June precipitation is only a trace on top peaks of Mount-Lebanon. Rainfall follows the topographic effect as in early fall and late spring. It is the period of zero rain over all Lebanon.

\subsection{Annual Precipitation Rate over All Lebanon}

Variability of precipitation was computed on pixels of $0.25^{\circ} \times 0.25^{\circ}$ overall Lebanon, using TRMM gridded data. Each pixel shows the mean annual precipitation for 18 years, which they are 1998-2014 and 2017. Annual precipitation ranged between about $200 \mathrm{~mm}$ in pixel C18 (east Lebanon) and $850 \mathrm{~mm}$ in pixel $\mathrm{C} 4$ and $\mathrm{C} 1$ (north coastal side) (Figure 4 and Figure 5). Pixels of north coastal Lebanon $(\mathrm{C} 1, \mathrm{C} 2, \mathrm{C} 3, \mathrm{C} 4, \mathrm{C} 5, \mathrm{C} 6, \mathrm{C} 9$ and $\mathrm{C} 10)$ received the highest precipitation rate between 700 and $850 \mathrm{~mm}$. In contrast, inland pixels of northeastern Lebanon (C22, C18, C17, C13 and C8) had the lowest annual precipitation rates that ranged between 200 and $450 \mathrm{~mm}$. These results differ when compared to the 1971 map of precipitation. In 1971, they may show concentration of rainfall only around middle of the country in the center of Mount-Lebanon.

The topographic effect on precipitation is highly noticeable once comparing pixels of littoral to inlands crossing the highest peaks of Mount Lebanon. This specific portion (north part) of Lebanon shows the orographic effect on rainfall distribution. Windward side of Mount Lebanon, north littoral part, receives humid sea air from the west that condenses over the high peaks and poor most of the rain. Across the mountain, drier air rains much less, forming semiarid zone.

Topographically related precipitation, in Lebanon, was found through Plassard's contribution in producing the precipitation map. Precipitation, on this map, increased from seashore to the top peaks of Mount-Lebanon. The map showed three maximum precipitation areas over the mountain. It also shows that Mount-Lebanon receives rainfall on similar rates throughout its spatial distribution, starting northeastern part of Mount-Lebanon toward the southwestern 


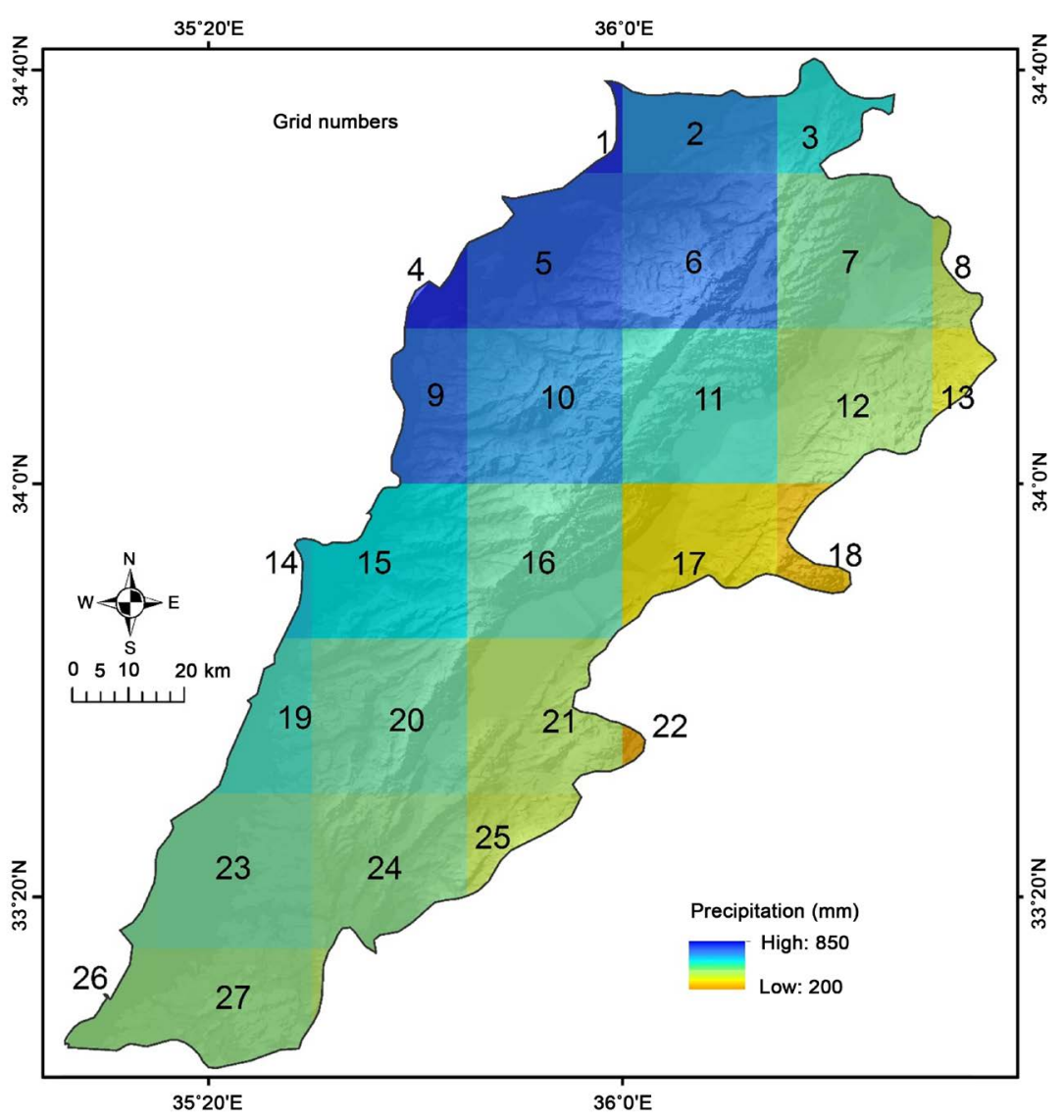

Figure 4. Pixel number between $\mathrm{C} 1$ and $\mathrm{C} 27$ overall Lebanon and the annual precipitation rates in $\mathrm{mm}$.

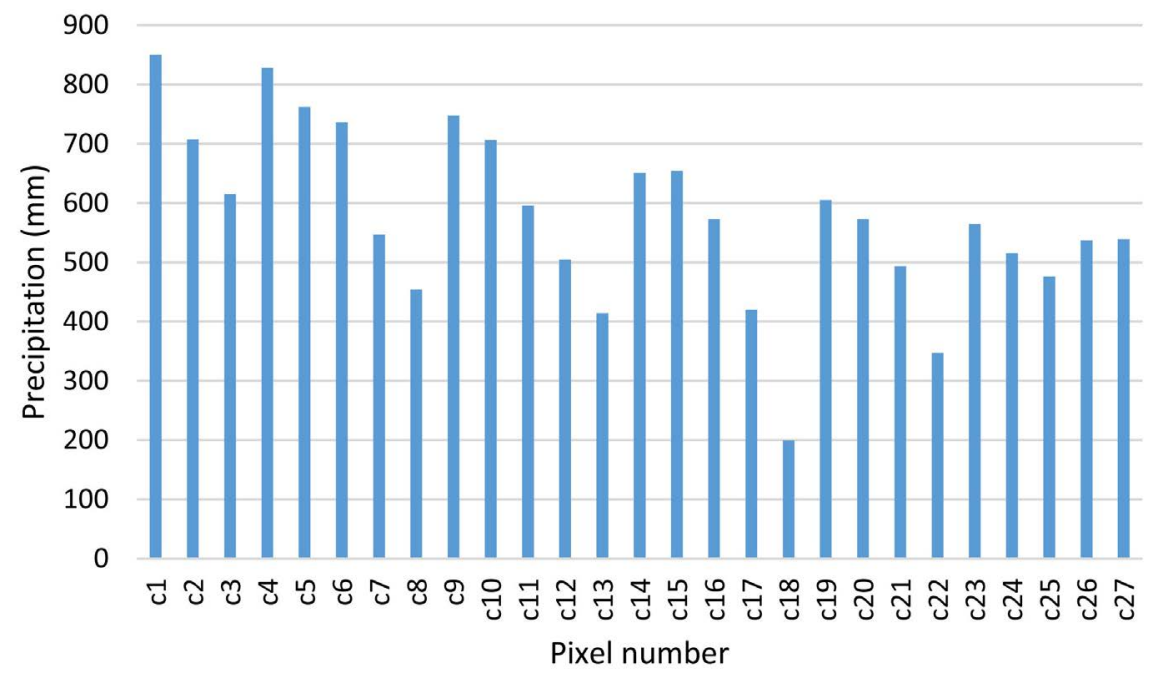

Figure 5. Precipitation distribution among the different pixels in Lebanon.

one. Another precipitation peak was also shown over the southern part of Anti-Lebanon (southeastern Lebanon at Mont Hermon-Jabal El Sheikh).

TRMM data showed that precipitation increases with elevation at the windward side of Mount-Lebanon, only at early fall and late spring, the months of 
September, May and June. However, in other rainy months this topographic effect does not show the trend of elevation vs precipitation demonstrated in Plassard's map. The map of Plassard clearly shows that all over the year the highest elevation, mountain peaks, receives higher precipitation rates (Figure 2). The maximum rainfall rate derived in the TRMM map was $850 \mathrm{~mm}$ with $700 \mathrm{~mm}$ less than Plassard's data.

On the other hand, TRMM data, contrariwise, demonstrates a trend of precipitation that decreases with topographic elevation at the windward side of Mount-Lebanon (Figure 4). There was, in TRMM mean annual precipitation map, no three main peaks of precipitation over Mount-Lebanon. TRMM data showed spatial distribution of precipitation starts high at the seashore and decreases upward to the mountain peaks. In addition, precipitation peak on Anti-Lebanon (southeast Lebanon) was not found, as it is the case on Plassard's map. TRMM mean annual map does not compare with Plassard's map but only in northeastern Lebanon, where precipitation is minimum. Precipitation over the Northeastern part of Lebanon is minimum that makes it comparable and close to what TRMM sensors provided [11].

\section{Conclusion and Perspectives}

North coastal zone showed high variability even with the $0.25^{\circ} \times 0.25^{\circ}$ pixel size. Such pixel size should play the role of normalization and should lower the spatial variability in precipitation distribution. Precipitation differences among pixels are largely pronounced following the topographic features of Lebanon. A 50 $\mathrm{mm}$ of precipitation difference between pixels in one month would accumulate throughout the year, approaching about 80 to $100 \mathrm{~mm}$. Rain gage spatial distribution must follow this variability in pixels and increase the number in higher margin pixels.

TRMM data might not capture high intensity rains because it records data every three hours. Thus, coastal areas of high intensity rainfall patterns might register much lower precipitation than expected. In inlands, precipitation is less intense, causing better registration over the three hours periods. [12] has found a similar assessment comparable to what this research paper found.

The spatial distribution of precipitation has to be searched in more investigation. A comparison of precipitation spatial distribution between maps of Plassard and the TRMM revealed pronounced dissimilarities. Mount-Lebanon peaks did not receive the highest rainfall rates when compared to seashore line precipitation. This dissimilarity repeated along the southeastern side of Anti-Lebanon. No precipitation peak was registered in the area of Anti-Lebanon in TRMM data.

Future studies would require investigating satellite precipitation data on longer data sets and in higher spatial/temporal resolution. TRMM data has to be monitored and compared on hourly basis to ground observation points of precipitation. This comparison would lead to a better knowledge of the best spatial 
distribution of rain gages and in further understanding about satellite data of precipitation. Monthly and daily investigation of precipitation variability is required for further comparison.

\section{Conflicts of Interest}

The authors declare no conflicts of interest regarding the publication of this paper.

\section{References}

[1] Villarini, G., Mandapaka, V.P., Krajewski, W.F. and Moore, R.J. (2008) Rainfall and Sampling Uncertainties: A Rain Gauge Perspective. Journal of Geophysical Research, 113, D11102. https://doi.org/10.1029/2007JD009214

[2] Arnaud, P., Bouvier, C., Cisneros, L. and Dominguez, R. (2002) Influence of Rainfall Spatial Variability on Flood Prediction. Journal of Hydrology, 260, 216-230. https://doi.org/10.1016/S0022-1694(01)00611-4

[3] Shaban, A., Robinson, C. and El-Baz, F. (2009) Using MODIS Images and TRMM Data to Correlate Rainfall Peaks and Water Discharges from the Lebanese Coastal Rivers. Journal of Resources and Protection, 4, 227-236. https://doi.org/10.4236/jwarp.2009.14028

[4] Yates, D., Purkey, D., Sieber, J., Huber-Lee, A., Galbraith, H., West, J., Herrod-Julius, S., Young, C., Joyce, B. and Rayej, M. (2009) Climate Driven Water Resources Model of the Sacramento Basin, California. Journal of Water Resources Planning and Management, 135, 303-313. https://doi.org/10.1061/(ASCE)0733-9496(2009)135:5(303)

[5] Cristiano, E., ten Veldhuis, M.C. and van de Giesen, N. (2017) Spatial and Temporal Variability of Rainfall and Their Effects on Hydrological Response in Urban Areas-A Review. Hydrology and Earth System Sciences, 21, 3859-3878. https://doi.org/10.5194/hess-21-3859-2017

[6] New, M., Todd, M., Hulme, M. and Jones, P. (2001) Precipitation Measurements and Trends in the Twentieth Century. International Journal of Climatology, 21, 1899-1922. https://doi.org/10.1002/joc.680

[7] Fischer, T., Zeng, Y. and Fraedrich, K. (2016) Evaluation of TRMM 3B43 Precipitation Data for Drought Monitoring in Jiangsu Province, China. Water, 8, 221. https://doi.org/10.3390/w8060221

[8] Chandrasekar, V., Srinivasa Ramanujam, K., Chen, H., Le, M. and Alqudah, A. (2014) Rainfall Estimation from Spaceborne and Ground Based Radars Using Neural Networks. IEEE Geoscience and Remote Sensing Symposium, Quebec City, 13-18 July 2014, 4966-4969. https://doi.org/10.1109/IGARSS.2014.6947610 https://ieeexplore.ieee.org/xpl/mostRecentIssue.jsp?punumber $=6919813$

[9] Plassard, J. (1971) Carte pluviométrique du Liban á l'échelle 1/200,000. Ministère des travaux publics. Direction Générale de l'Aviation Civile.

[10] Huffman, G.J., Adler, R.F., Rudolf, B., Schneider, U. and Keehn, P.R. (1995) Global Precipitation Estimates Based on a Technique for Combining Satellite-Based Estimates, Rain Gauge Analysis, and NWP Model Precipitation Information. Journal of Climate, 8, 1284-1295. https://doi.org/10.1175/1520-0442(1995)008<1284:GPEBOA >2.0.CO;2

[11] Jomaa, I., Skaf, S., Massaad, R. and Elhaj, N. (2011) Variabilité climatique au Liban. Actes de Coloque; Environnement et Gestion Durable de Ecosystemes Naturels au 
Moyen-Orient. 18-20 April, 2011, AUF, Beirut.

[12] Chokngamwong, R. and Chiu, L.S. (2008) Thailand Daily Rainfall and Comparison with TRMM Products. Journal of Hydrometeorology, 9, 256-266.

https://doi.org/10.1175/2007JHM876.1 